\title{
PLANT SPECIES INVASIONS ALONG THE LATITUDINAL GRADIENT IN THE UNITED STATES
}

\author{
Thomas J. Stohlgren, ${ }^{1,6}$ David Barnett,${ }^{2}$ Curtis Flather,${ }^{3}$ John Kartesz, ${ }^{4}$ And Bruce Peterjohn ${ }^{5}$ \\ ${ }^{1}$ National Institute of Invasive Species Science, U.S. Geological Survey, Fort Collins Science Center, \\ Fort Collins, Colorado 80526 USA \\ ${ }^{2}$ Natural Resource Ecology Laboratory, Colorado State University, Fort Collins, Colorado 80523 USA \\ ${ }^{3}$ USDA Forest Service, Rocky Mountain Research Station, Fort Collins, Colorado 80526 USA \\ ${ }^{4}$ Biota of North America Program, University of North Carolina, Chapel Hill, North Carolina 27599 USA \\ ${ }^{5}$ Patuxent Wildlife Research Center, U.S. Geological Survey, 12100 Beech Forest Road, Laurel, Maryland 20708 USA
}

Abstract. It has been long established that the richness of vascular plant species and many animal taxa decreases with increasing latitude, a pattern that very generally follows declines in actual and potential evapotranspiration, solar radiation, temperature, and thus, total productivity. Using county-level data on vascular plants from the United States (3000 counties in the conterminous 48 states), we used the Akaike Information Criterion (AIC) to evaluate competing models predicting native and nonnative plant species density (number of species per square kilometer in a county) from various combinations of biotic variables (e.g., native bird species density, vegetation carbon, normalized difference vegetation index), environmental/topographic variables (elevation, variation in elevation, the number of land cover classes in the county, radiation, mean precipitation, actual evapotranspiration, and potential evapotranspiration), and human variables (human population density, cropland, and percentage of disturbed lands in a county). We found no evidence of a latitudinal gradient for the density of native plant species and a significant, slightly positive latitudinal gradient for the density of nonnative plant species. We found stronger evidence of a significant, positive productivity gradient (vegetation carbon) for the density of native plant species and nonnative plant species. We found much stronger significant relationships when biotic, environmental/topographic, and human variables were used to predict native plant species density and nonnative plant species density. Biotic variables generally had far greater influence in multivariate models than human or environmental/topographic variables. Later, we found that the best, single, positive predictor of the density of nonnative plant species in a county was the density of native plant species in a county. While further study is needed, it may be that, while humans facilitate the initial establishment invasions of nonnative plant species, the spread and subsequent distributions of nonnative species are controlled largely by biotic and environmental factors.

Key words: native plant species; non-indigenous plant species; patterns of invasion; species densities.

\section{INTRODUCTION}

General ecological theories about the patterns of biological diversity provided competing hypotheses for this study. On one hand, von Humboltd (1808), Currie (1991), Huston (1979, 1994), Rosenzweig (1995), and Hawkins et al. (2003) described a fairly consistent trend of decreasing richness of vascular plants, birds, mammals, amphibians, and reptiles with increasing latitude and co-varying environmental factors. The pattern followed declines in actual and potential evapotranspiration (AET, PET) and solar radiation, with optimal conditions for growth and productivity associated with the peaks in richness (Currie 1991; but see Huston

Manuscript received 29 July 2004; revised 23 November 2004; accepted 29 November 2004. Corresponding Editor: B. A. Hawkins. For reprints of this Special Feature, see footnote 1, p. 2261.

${ }^{6}$ E-mail: tom_stohlgren@USGS.gov
[1999]). The theory that species richness is largely determined by environmental factors is sometimes called "local determinism" (Ricklefs 2004). It logically follows that these relationships might be similar for both native and nonnative plant species, assuming they respond similarly to energy and resource availability. We refer to this as the "environment-matching hypothesis."

On the other hand, it also follows from theories of plant invasions that competition for available resources and subsequent resource limitations could constrain species coexistence, especially if newly arriving small seeds of nonnative species must compete with wellestablished, mature, native plants (Stohlgren et al. 2003). If available niches are filled with many native species, and if competition for resources were a strong, broad-scale force in nature, we might expect to see negative relationships between native and nonnative species richness (or densities) in local or regional flo- 
ras. This has been broadly termed "competitive exclusion theory" (Grime 1973).

Humans increase the complexity of the issue and, potentially, the uncertainty associated with any analyses of patterns of native and nonnative species plant richness. Humans may have settled in native speciesrich areas or may have introduced nonnative species to those areas or adjacent species-poor areas. Further establishment and spread of invasive nonnative species may be a complex function of human-caused and natural disturbances, land-use change, and environmental conditions, along with the complex traits and autecology of the invading and resident species.

Understanding the patterns of native species richness at local, landscape, and regional scales may further our understanding of invasion by nonnative species. Some landscape-scale surveys of plant diversity in the United States have shown significant positive relationships between native and nonnative plant species richness in 0.1-ha plots in the Central Grasslands, Rocky Mountains of Colorado, and arid ecosystems in southern Utah (Stohlgren et al. 1997, 1998, 1999a, 2001, 2002). In many cases, native and nonnative species richness was positively correlated to soil fertility and water availability. Preliminary county-level data showed that native plant species richness was positively correlated to nonnative species richness in 45 of 46 states (Stohlgren et al. 2003). Still, little is known about the abiotic and biotic factors associated with national-scale patterns of plant species distributions.

It is intuitive that factors other than latitude more directly influence plant species richness and that latitude is cross-correlated with AET, PET, precipitation, mean annual temperature, solar radiation, and other factors (Currie 1991, Rosenzweig 1995, Hawkins et al. 2003). Given the complex topography of the United States, predominantly north-south mountain ranges, and elevation and rain shadow effects, productivity may be a better surrogate of optimum growth conditions than latitude. We anticipate that native and nonnative plant species densities may be affected by optimal combinations of warm temperatures, high light, water, and nutrient availability (for carbon accumulation) and by avoiding high stress, extreme environments such as very high latitudes and elevations, or extremely arid or low-light environments. Habitat heterogeneity and moderate levels of disturbance also may increase species richness (Huston 1994, 1999), so we included the variation in elevation and the number of land cover classes in a county as simple measures of habitat variation.

The role of modern humans in altering species distributions cannot be denied. Direct habitat loss and intentional invasive species introductions have been directly linked to human habitation (Soulé 1991 $a, b$, Wilcove et al. 1998), and approximately $60 \%$ of humans live within approximately $170 \mathrm{~km}$ of the ocean (or sea; Hindrichson 1997). Since the introduction of non-indigenous species is largely human-induced (via trade, modern transportation, and urbanization patterns), we included human population density and road density in the list of potential drivers of the patterns of species introductions. Approximately $60 \%$ of the invasive nonnative plant species were escaped horticultural or agricultural products (Reichard and White 2001). Since many nonnative plant seeds arrived as contaminants with forage crops and are thought to become initially established on disturbed sites (Reichard and White 2001), we included percentage of cropland area in a county and percentage of disturbed lands (e.g., cultivated land, mining, urban areas) as "human" variables in regression analyses. Currie (1991), Huston (1994), Rosenzweig (1995), and Hawkins et al. (2003) do not directly discuss modern patterns of diversity resulting from the exchange of species among continents and habitats. Our analysis may complement these works by evaluating native and nonnative plant species densities at a large spatial scale.

We assessed preliminary trends in native and nonnative plant species densities with a large county-level data set on vascular plant distributions in the United States. Our objectives were to: (1) evaluate simple patterns of native and nonnative plant species density (number of species per square kilometer in a county) related to latitude and productivity (total vegetation carbon) gradients in the continental United States; and (2) use the Akaike Information Criterion and information-theoretical model selection to provide a more detailed evaluation of competing models explaining native and nonnative plant species density relative to various combinations of biotic, environmental/topographic, and human variables.

\section{Methods and Statistical Approach}

The plant data set was gathered over the past 35 years by the Biota of North America Program (BONAP). The taxonomic accuracy and completeness of the collection have made it the standard plant data set for many government and nongovernment agencies. The data set included the occurrence of over 22800 native and 3726 nonnative plant taxa in 3114 counties in the 48 conterminous states. Nonnative plant species were defined as those plant species with origins in other countries. This distinction is nonambiguous and well accepted. Nonnative plant species records reflect all past introductions, including some species that have not been recently reported. Due to incomplete data on current species distributions, we assumed that the patterns of past introductions are only a first approximation of current introduction patterns. To further protect against the influence of incomplete data in some counties, all counties with fewer than 100 native plant species recorded were removed from analyses, leaving 3000 counties in the continental United States.

Because counties vary greatly in area (from $59 \mathrm{~km}^{2}$ for New York County, New York, to over $52000 \mathrm{~km}^{2}$

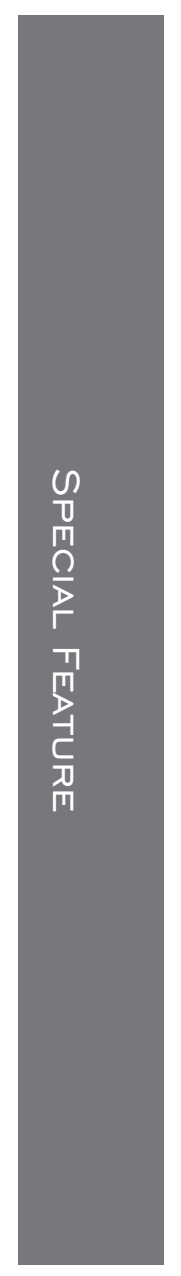


for San Bernadino County, California), we used the density of native and nonnative plant species as primary dependent variables in regression analyses. We investigated several models of species densities. Preliminary species-area analyses showed that "area" explained little of the variation in native species richness $\left(r^{2}=0.16\right)$ and nonnative species richness $\left(r^{2}=0.001\right)$, while equal or lesser amounts of variation were explained by relationships to $\log _{10}$ (area) $\left(r^{2}=0.11\right.$ and 0.0001 , respectively). Thus, many other factors related to the environment, habitat heterogeneity, land-use change, disturbance history, and evolutionary history may be more important than area in influencing species richness. Still, because there were significant effects of area (in a statistical sense), it could not be ignored. We concluded that simple measures of species density (number of species per square kilometer) would work as well or better than more complex models of density at these spatial scales. This reduced the effect of area when comparing data among counties, but we realize that eastern U.S. counties were considerably smaller on average and that finer resolution analyses (below the county level) would have been preferred, but the data do not exist for such analyses.

We initially considered 13 environmental/topographic variables including latitude, mean elevation, and variation in elevation in a county, mean minimum temperature, mean annual temperature, mean annual precipitation, actual and potential evapotranspiration, solar radiation, humidity, and the number of frost-free days and growing degree-days. However, to reduce statistical problems related to multicollinearity (Neter et al. 1990, Burnham and Anderson 2002), we screened out variables that were highly cross-correlated $(r>$ \pm 0.80 ; Bonferroni tests, transformed data where necessary; Appendix). For example, latitude and mean temperature were highly related to PET $(r>0.91)$, and PET was considered a more direct driver of plant diversity, so latitude and mean temperature were dropped from further analysis. Likewise, minimum temperature, humidity, frost days, and growing degree-days were excluded, leaving seven environmental/topographic variables (Appendix).

Human factors included human population, road density, percentage of cropland in a county, and an index of habitat disturbance (ratio of area disturbed [developed, cultivated, and surface mines] to total county area; Appendix). However, since road density was highly correlated with human population density $(r=0.85)$, it was excluded from further analysis (Appendix).

Biotic variables initially included vegetation carbon and the normalized difference vegetation index (NDVI). Plant productivity is difficult to measure because it involves aboveground and belowground components, changes seasonally and annually, and is prohibitively expensive to measure at large spatial scales. We relied on two surrogates for productivity (potential aboveground total vegetation carbon) based on a 30yr annual mean (1961-1990) measured as grams of carbon per square meter at 3168 locations in the United States, then kriged to county centroids (VEMAP2 DATA, 2000, National Center for Atmospheric Research, Boulder, Colorado, USA; Hof et al. 2004) and NDVI (see Appendix for details). Vegetation carbon provided a commonly used estimate of a productivity gradient to compare with latitude and other variables.

An additional biotic measure of habitat heterogeneity included native bird species density. In another paper (Stohlgren et al. 2005), we demonstrated that the density of native bird species in a county (nesting birds only) integrated elements of high productivity, high habitat heterogeneity, and moderate disturbance as has been found in other studies (Rosenzweig 1995). Because the density of bird species also integrates many aspects of the environment at global scales (Currie 1991), we used the density of native bird species in a county as an independent variable in models to predict native and nonnative plant species densities. Native bird species data were compiled at the USGS Patuxent Wildlife Research Center, Maryland, USA, producing species richness data for 3079 counties across 50 states. For 36 states, distribution data were obtained from published breeding bird atlas projects conducted between the mid-1970s and the late 1990s. Various state and regional publications provided county-level distribution information for states lacking published atlases.

We hypothesized that mean native and nonnative plant species density within counties for the conterminous United States would be more closely associated with productivity gradients rather than latitude gradients. We further hypothesized that because biota may integrate coarse- and fine-scale environments and habitat heterogeneity, biotic variables would more strongly predict native and nonnative plant species densities compared to either environmental/topographic variables or human variables. We tested only two models on a preliminary set of data (Stohlgren et al. 2005), so we updated the data set and expanded the analysis to an a priori suite of models designed to test our primary hypothesis that biotic variables would better describe patterns of native and nonnative species densities at county scales compared to environmental/topographic and human variables.

We assessed cross-correlations among vegetation carbon, NDVI, bird species density, and the environmental/topographic and human variables using pairwise comparisons and Bonferroni tests of significance (Systat version 10; SYSTAT Software, Port Richmond, California, USA), and no egregious cross-correlations were found $(r>0.80)$. We conducted stepwise multiple regressions to remove insignificant predictors from the models $(P>0.15)$, to remove additional variables with high tolerance levels $(>0.95$; none were found), and to assure that no significant predictors were ignored. Lastly, model residuals were inspected for underlying 
patterns (Zar 1974), and none were found. Significant values in all cases were determined using the SYSTAT statistical software (version 10).

We used the Akaike Information Criterion (AIC) and information-theoretical model selection (Burnham and Anderson 2002) to evaluate multiple regression models related to the specific hypotheses above. While this approach may not produce the "best" model as compared to other computationally intensive approaches, it does allow for direct comparisons among multiple models.

For least-squares regressions, we assumed normally distributed errors (a fair first approximation in our case), and AIC was computed as

$$
\mathrm{AIC}=n \log (\mathrm{RSS} / n)+2 K
$$

where $n$ was the sample size, RSS was the residual sum of squares in the model such that RSS/ $n$ is the maximum likelihood estimator, and $K$ was the number of estimable parameters in the model (including the intercept and residual variance; Burnham and Anderson 2002:63). The differences in AIC values between the best model (lowest AIC) and other models were used to rank the models in relation to their support based on the data.

\section{RESULTS}

\section{Latitudinal gradients of plant species density}

Regression analyses showed no relationship between latitude and native plant species density $\left(r^{2}=0.0001\right.$, $P=0.60$; Fig. 1). There was a statistically significant but biologically meaningless positive relationship between latitude and nonnative plant species density $\left(r^{2}\right.$ $=0.01, P=0.0001 ;$ Fig. 1$)$.

\section{Productivity gradients of plant species density}

Plant species density was more strongly correlated to total vegetation carbon than to latitude. Higher native and nonnative plant species densities were associated with areas of high total vegetation carbon (Fig. 2). Total vegetation carbon explained approximately $22 \%$ of the variation in native species densities and $7 \%$ of the variation in nonnative species densities. There were several counties moderately high in vegetation carbon with high values of native and nonnative plant species density, but these were offset by a large number of counties with low densities of species (Fig. 2).

\section{Cross-correlations among variables}

We found many cross-correlations among factors related to latitude and total vegetation carbon that can confound or help interpret patterns of plant species density (Table 1). Native and nonnative plant species density were strongly positively correlated to bird species density, and these three biotic variables were positively correlated to vegetation carbon and NDVI. All the biotic variables were positively correlated to pre-
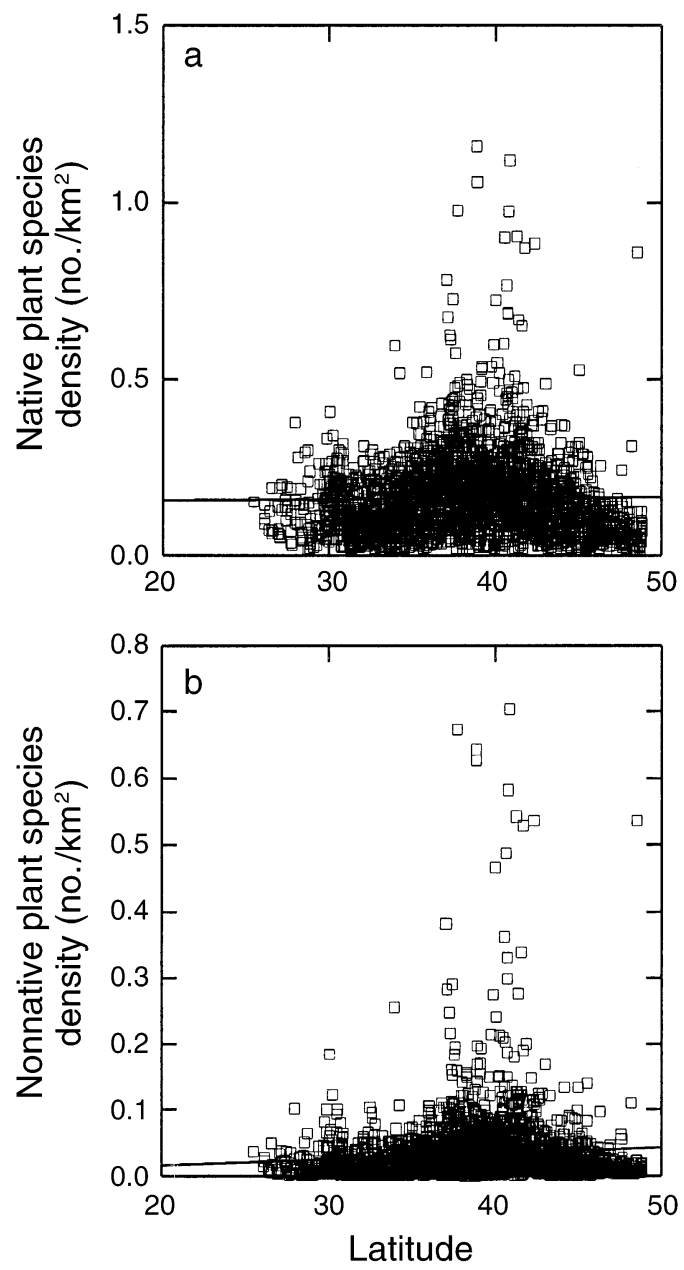

FIG. 1. Regressions of species density in a county on latitude for (a) native plant species $\left(r^{2}=0.0001, P=0.60\right)$ and (b) nonnative plant species $\left(r^{2}=0.01, P=0.0001\right)(n$ $=3000$ counties in 48 states of the United States). Data were $\log$ transformed.

cipitation and negatively correlated to radiation, elevation, and the variation in elevation in a county. Potential evapotranspiration, which was strongly correlated to latitude, and AET were positively correlated to one another and to precipitation and negatively correlated to elevation and variation in elevation (Table 1).

Solar radiation was negatively correlated to vegetation carbon. This shows the potentially confounding geographic patterns in the United States where there are significant positive correlations between latitude and elevation and between latitude and the variation in elevation in a county. This describes the geography and topography of the United States due to north-southoriented mountain ranges (e.g., Rocky Mountains, Sierra Nevada, Cascade, and Appalachian ranges), which intercept precipitation and cause rain shadow effects with west-to-east-moving jet streams. 

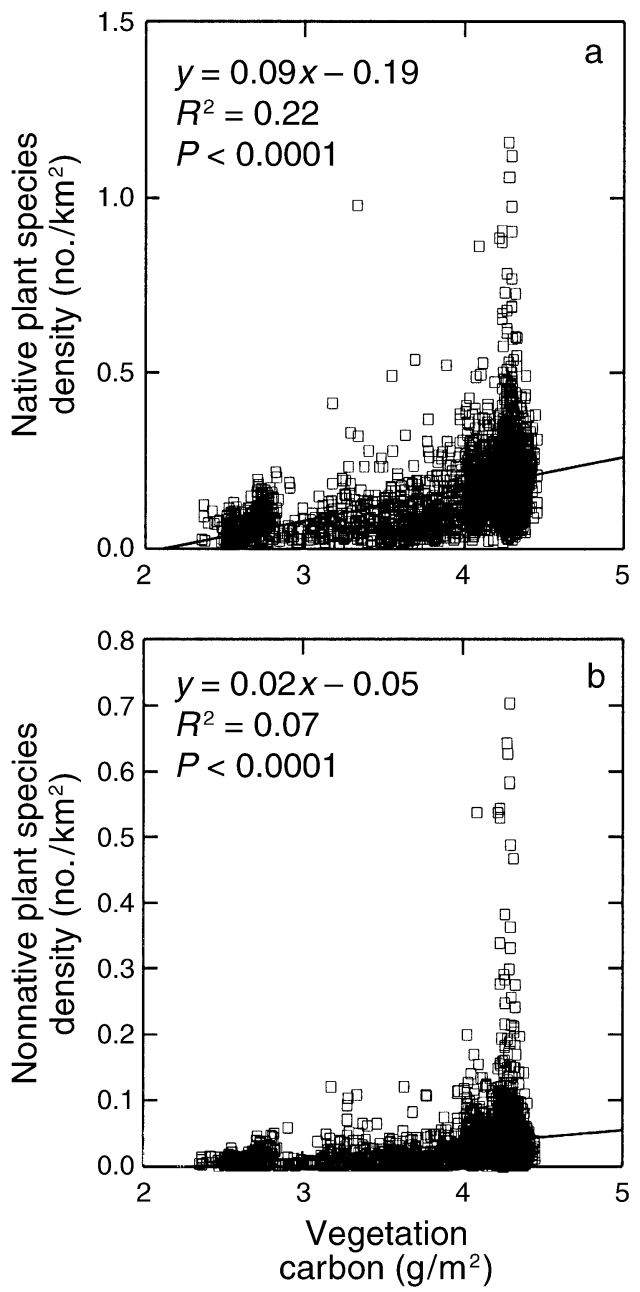

FIG. 2. Regressions of species density in a county on productivity (total vegetation carbon) for (a) native and (b) nonnative plant species ( $n=3000$ counties in 48 states). Data were $\log$ transformed.

Human population was strongly positively correlated to native and nonnative plant species density, native bird species density, and vegetation carbon, while cropland area was negatively correlated with these variables. The percentage of disturbed habitat in a county was weakly but positively associated with native and nonnative plant species density and with bird species density in a county (Table 1 ).

In the initial screening of the variables, growing degree-days, minimum and mean annual temperature, precipitation, PET, and AET were all significantly negatively correlated with latitude. However, latitude and temperature variables were replaced with PET for the multivariate models that follow.

\section{Information-theoretical models of plant species density}

The best single model describing the density of native plant species included all biotic, environmental/ topographic, and human variables (Table 2, model 1). This model had the smallest (most negative) AIC value of -16691 and explained $69 \%$ of the variation in native plant species density. Of the 15 individual variables used in the model, the most important predictors based on standardized partial regression coefficients $\left(S_{b}\right)$ included a positive relationship to native bird species density $\left(S_{b}=0.50\right)$ and negative relationships to elevation $\left(S_{b}=-0.24\right.$ and PET $S_{b}=-0.24$; also read latitude).

Three other models explained $63-67 \%$ of the variation in native plant species density (models $2-4$; Table 2), but strict adherence to information-theory modeling would suggest that the data do not support models 2 through 7 because the AIC differences $\left(\Delta \mathrm{AIC}_{i}=\mathrm{AIC}_{i}\right.$ - $\mathrm{AIC}_{\mathrm{min}}$, where $i$ indexes competing models) greatly exceed 10 (see Burnham and Anderson [2002:70]). In the models that included biotic factors (models 1-4), the strongest single predictor variable was native bird species density $\left(S_{\mathrm{b}} \geq 0.50\right)$. In the models that included environmental/topographic variables, negative relationships with PET and elevation were strong predictors of native plant species diversity. In general, for the seven models describing native plant species density, models including biotic variables performed better than models including human variables or environmental/topographic variables (Table 2).

Initially, the best single model describing the density of nonnative plant species also included biotic, environmental/topographic, and human variables (Table 3, model 8). In predicting nonnative plant species density, we could use the native plant species density as an independent variable because the native species were well entrenched for millennia prior to the arrival of nonnative species from other countries. Model 8 had the smallest (most negative) AIC value of -24055 , explained $86 \%$ of the variation in non-native plant species density, and was driven largely by the positive relationship with native plant species density $\left(S_{\mathrm{b}}=\right.$ $0.66)$. This is a stronger model (in terms of $R^{2}$ values) than model 1 for native plant species density, but the models included different independent variables, so a direct comparison of models is impossible. Model 8 excluded NDVI, mean precipitation, land cover, and variation in elevation $(P>0.15)$. In the five models that used biotic factors (models 8-12; Table 3), the most important predictor was the positive relationship to native plant species density $\left(S_{\mathrm{b}} \geq 0.66\right)$, and four models also included the density of native bird species in the top three predictors $\left(S_{\mathrm{b}} \geq 0.21\right)$.

Four other models explained $75-85 \%$ of the variation in nonnative plant species density, models 9-12, the latter being a simple linear model (Table 3 ). However, strict adherence to information-theory modeling again would suggest that the data do not support these other models.

Lastly, in a post hoc model, we found a highly significant positive, nonlinear relationship between native 
and nonnative plant species density, with $90 \%$ of the variation in nonnative plant species density explained solely by the density of native plant species in a county (Fig. 3). Had we included this model in our original suite (Table 3 ), its AIC $=-25125$ would have made it the "best model." We tested the model regionally in selected areas of the United States and found that between $64 \%$ and $98 \%$ of the variation in nonnative species densities could be explained solely by the density of native plant species (Table 4).

It is worth noting that model rank order based on AIC from best to least supported given our data is identical to the ranking based on adjusted $R^{2}$ (Tables $2,3)$. In fact, the correlation between those two statistics exceeds 0.96 for both native and nonnative species density response variables (unreported data). Although we were initially surprised by this pattern, it is clear from Eq. 1 that when dealing with consistently large sample sizes $(n=3000)$ and $K$ s that vary little $(3-15)$ most of the variation in AIC will be captured by the residual sum of squares. Since that term is shared by AIC and adjusted $R^{2}$ the common rank orders should have been anticipated.

\section{DISCUSSION}

\section{Understanding optimal conditions for plant species density}

The weak relationship between latitude and native species density in the conterminous United States (Fig. 1) might be expected due to north-south-oriented mountain ranges, which affect precipitation patterns and cause rain shadow effects with west-to-east-moving jet streams. That is, sites of similar latitude on the western and eastern sides of a mountain range will have very different environments, species compositions, and likely species densities. Several authors discuss the limitations of latitude as an environmental predictor of species richness (Huston 1999, Hawkins et al. 2003, Hawkins and Diniz-Filho 2004). However, the observed productivity gradient with native and nonnative plant species densities more strongly suggests that native and nonnative plant species may be responding to similar environmental constraints (Fig. 2), providing a link to similar global-scale energy patterns (Rosenzweig 1995) and water-driven patterns of plant diversity (see Hawkins et al. [2003] for a review). Because vegetation carbon was correlated more strongly with precipitation $(r=0.78)$ than with radiation $(r=$ $-0.20)$, mean annual temperature $(r=0.31)$, PET $(r$ $=0.24)$, or AET $(r=0.61$; all $P<0.0001)$, our data corroborate the Hawkins et al. (2003) conclusion that water may be a major driver of species richness in the continental United States.

However, energy (solar radiation and temperature) also may play an important role in plant species density. The consistent significant negative relationships between all the biotic variables and both elevation and radiation, negative relationship between mean annual temperature and elevation $(r=-0.62 ; P<0.0001)$, and positive relationship between mean annual temperature and vegetation carbon $(r=0.31 ; P<0.0001)$ suggest that optimal conditions for productivity involve the interactions of energy and water (Hawkins et al. 2003). There is growing evidence that diversity peaks at those places with optimal conditions for growth and productivity (Currie 1991, Rosenzweig 1992, Badgley and Fox 2000, Hawkins et al. 2003; but see Huston [1979, 1994]).

\section{Multiple models and multiple variables associated with plant species density}

Multiple models of native plant species diversity included all the variables inserted in the models (Table 2 , model 1), initially complicating our understanding of the factors predicting patterns of native plant species diversity. All the subsequent models (Table 2, models $2-7$ ) would be dismissed based on the $\Delta$ AIC criterion, and we did not expect the model based on environmental/topographic variables (model 6) to perform the worst of the seven models. It was instructive that models that included biotic factors performed better than models based strictly on environmental/topographic and human variables. The importance of humans might be dismissed on the grounds that humans settled in species-rich areas rather than "causing" species-rich areas (Stohlgren et al. 2005). In this study, the best model of nonnative plant species density ultimately supported by the data (Fig. 3) also excluded human variables. It was more informative to recognize that the primary predictor variables in the best model of native plant species density (Table 2, model 1) were native bird species density, elevation, and PET (biotic and environmental variables).

Biotic factors may integrate complex and coarseresolution environmental/topographic data. In loosely comparing the models for native plant species density (models 1-7; Table 2) and the models for nonnative species density (models $8-15$, excluding model 12; Table 3), the AIC rankings of two sets of models were unexpectedly identical, suggesting: (1) generally biotic variables $\gg$ human variables $\approx$ environmental/topographic variables in describing patterns of native and nonnative plant species density, and (2) the dominant predictor biotic variable for native plant species density was always native bird species density, while the dominant predictor biotic variable for nonnative plant species density was always native plant species density. It may be that native plant and bird species densities summarize species richness data from rare and common habitats in a county and, as such, integrate micro- and macroenvironments, and disturbed and undisturbed habitats that are not adequately represented by mean environmental/topographic or human variables at county scales. 
TABLE 1. Cross-correlations (Pearson coefficients) among selected biotic, environmental/topographic, and human variables.

\begin{tabular}{|c|c|c|c|c|c|c|c|}
\hline Variable & $\begin{array}{l}\text { Native } \\
\text { plant } \\
\text { density }\end{array}$ & $\begin{array}{c}\text { Nonnative } \\
\text { plant } \\
\text { density }\end{array}$ & $\begin{array}{l}\text { Native } \\
\text { bird } \\
\text { density }\end{array}$ & $\begin{array}{l}\text { Vegetation } \\
\text { carb. }\end{array}$ & NDVI & Elevation & $\begin{array}{l}\text { Variation in } \\
\text { elevation }\end{array}$ \\
\hline Native plant density & 1.00 & & & & & & \\
\hline Nonnative plant density & 0.86 & 1.00 & & & & & \\
\hline Native bird density & 0.76 & 0.77 & 1.00 & & & & \\
\hline Vegetation carbon & 0.46 & 0.26 & 0.34 & 1.00 & & & \\
\hline NDVI & 0.26 & 0.14 & 0.18 & 0.38 & 1.00 & & \\
\hline Elevation & -0.33 & -0.27 & -0.29 & -0.49 & -0.14 & 1.00 & \\
\hline Variation in elevation & -0.20 & -0.14 & -0.23 & -0.29 & -0.25 & 0.76 & 1.00 \\
\hline Land cover & -0.15 & -0.11 & -0.20 & NS & -0.44 & -0.11 & 0.13 \\
\hline Radiation & -0.28 & -0.26 & -0.25 & -0.20 & -0.72 & 0.15 & 0.21 \\
\hline Precipitation & 0.35 & 0.18 & 0.26 & 0.78 & 0.41 & -0.57 & -0.33 \\
\hline $\mathrm{AET}^{1}$ & 0.24 & NS & 0.18 & 0.61 & 0.26 & -0.70 & -0.66 \\
\hline PET & $-0.06 \ddagger$ & -0.10 & NS & 0.24 & -0.27 & -0.61 & -0.47 \\
\hline Human population density & 0.59 & 0.70 & 0.55 & 0.23 & NS & -0.28 & -0.13 \\
\hline Crop area & -0.37 & -0.25 & -0.34 & -0.50 & 0.09 & 0.20 & -0.11 \\
\hline Disturbance & 0.12 & 0.15 & 0.12 & -0.07 & 0.37 & -0.11 & -0.46 \\
\hline
\end{tabular}

Notes: Transformed data were used where it was appropriate. Correlations are significant at $P<0.05$ except where noted; NS $=P>0.1$. NDVI, normalized difference vegetation index; AET, actual evapotranspiration; PET, potential evapotranspiration.

$\dagger P=0.06$

$\ddagger P=0.09$.

The post-hoc nonlinear model of native to nonnative plant species density (Fig. 3), the new best model examined in terms of both AIC and adjusted $R^{2}$, further suggests that the total environmental conditions conducive to high native plant species densities may create environmental conditions conducive to the establishment of nonnative species. Since many factors are significantly cross-correlated with latitude, including productivity, solar radiation, AET, PET, mean annual temperature, mean minimum temperature, and precipitation, it's not surprising that native and nonnative plant species densities also are significantly cross-correlated to these same variables. And, despite the fact that all these factors vary enormously in various regions of the country, a single, strong predictor of nonnative species density in selected regions (Table 4), and in the conterminous United States (Fig. 3), is the density of native plant species.

\section{Patterns that cross spatial scales}

There is growing evidence that a few environmental factors may explain species richness patterns at landscape scales (Stohlgren et al. 1997, 2002, Chong et al. 2001), continental and regional scales (Stohlgren et al. 2005a), and global scales (Currie 1991, Huston 1994, Rosenzweig 1995, Kleidon and Mooney 2000, Allen et al. 2002, Hawkins et al. 2003). For example, in Rocky Mountain National Park, Colorado, mesic mountain meadows and aspen (Populus tremuloides) habitats that were high in light, nitrogen, and water had higher native and non-plant species densities (per 0.1ha plot) and overall richness based on multiple plots (Stohlgren et al. 1997, 1999a). High-elevation sites had far fewer nonnative species than low-elevation sites. Likewise, mesic vegetation types in the xeric Grand
Staircase-Escalante National Monument, Utah, with soils high in nitrogen and phosphorus, had higher native and nonnative plant species densities (per 0.1-ha plot) and overall richness based on multiple plots (Stohlgren et al. 2002). From the shortgrass steppe sites to tallgrass prairie sites in the central grasslands of the United States, native-species-rich areas were more heavily invaded (i.e., in nonnative plant species richness and foliar cover) than species-poor sites (Stohlgren et al. 2001). At statewide scales, California has the greatest number of native and nonnative plant species, coinciding with high habitat heterogeneity, large area, complex topography and paleobotany, and mix of climate zones (Dobson et al. 1997, Stein et al. 2000; Table 4). The richness of plant species and many other biological groups (e.g., bird species density in this study) is often associated with high habitat heterogeneity (Rosenzweig 1992, 1995), but coarse-scale measures like land cover classes and variation in elevation (Table 1) may not sufficiently describe important microhabitats at county scales. At national scales, there is an overwhelming positive relationship between native and nonnative plant species richness (Stohlgren et al. 2003) and densities (Stohlgren et al. 2005) in counties, states, and regions.

Our study seems to support some aspects of what Ricklefs (2004) called "local determinism," despite some unexplained variation potentially due to local and regional species pools, patterns of endemism, varying levels of disturbance, and human factors (Huston 1999). Other studies also report that native plant species density in a region may be a complex function of habitat heterogeneity, warm temperatures, and/or precipitation (Rosenzweig 1995, Hawkins et al. 2003, Venevsky and Veneskaia 2003). 
TABle 1. Extended.

\begin{tabular}{|c|c|c|c|c|c|c|c|}
\hline Land cover & Radiation & Precipitation & AET & PET & $\begin{array}{c}\text { Human } \\
\text { population } \\
\text { density }\end{array}$ & Crop area & Disturbance \\
\hline
\end{tabular}

\begin{tabular}{|c|c|c|c|c|c|c|c|}
\hline 1.00 & & & & & & & \\
\hline 0.38 & 1.00 & & & & & & \\
\hline-0.10 & -0.23 & 1.00 & & & & & \\
\hline$-0.06 \dagger$ & NS & 0.73 & 1.00 & & & & \\
\hline 0.24 & 0.49 & 0.38 & 0.67 & 1.00 & & & \\
\hline NS & -0.14 & 0.17 & 0.08 & NS & 1.00 & & \\
\hline-0.12 & -0.16 & -0.42 & -0.23 & -0.15 & -0.23 & 1.00 & \\
\hline-0.29 & -0.38 & -0.10 & 0.08 & -0.10 & 0.16 & 0.64 & 1.00 \\
\hline
\end{tabular}

Local determinism has notable exceptions, typically where unique evolutionary history plays a significant role (Gentry 1986, Venevsky and Veneskaia 2003). Some arid landscapes with infertile soils, such as the fynbos region of South Africa (Bond 1983, Cowling et al. 1998), southwest Australia (Abbott 1977, Abbott and Black 1980), and the southwestern United States (Dobson et al. 1997), are hotspots of high plant endemism and diversity. However, more of the globe conforms to the general "hotspots" pattern closely associated with tropical and subtropical areas with abundant solar radiation and rainfall (Rosenzweig 1995, Myers et al. 2000). At landscape scales, some endemic species may be associated with arid environments such as desert habitats in southern Utah (Stohlgren et al. 2004), but in these and other areas throughout the United States, species-rich habitats also are common in highly productive areas with fertile soils, mesic habitats, and low-elevation areas. In the continental United States and at county scales, this pattern is corroborated by our finding that native species densities are positively correlated with potential vegetation carbon (Tables 1 and 2, Fig. 2). However, highly productive sites that have not been recently disturbed and where trees gain dominance may have low understory plant and bird diversity. These sites may rarely cover entire counties, and they may be less common (in terms of area) at regional scales.

Realizing that exceptions exist, this present study now provides a framework to evaluate general patterns of plant density. The relatively high predictability of native and nonnative species densities at subcontinental scales $\left(R^{2}=0.68\right.$ and 0.90 , respectively; Table 2 and Fig. 3) strongly supports similar global patterns and proposed mechanisms reported where declining diversity predictably coincides with harsh environments (Currie 1991, Rosenzweig 1995, O’Brian 1998, Francis and Currie 2003, Hawkins et al. 2003, Venevsky and Veneskaia 2003, Stohlgren et al. 2005).

\section{Predictable patterns of invasions of nonnative plant species}

The patterns and relationships presented here are preliminary. Additional data on native and nonnative plant distributions may improve our findings. Most counties are incompletely surveyed, and the additions of vegetation plot data, species lists from parks and refuges, and other point locations of plant species will improve sparsely surveyed counties (Crosier and Stohlgren 2004). We would also benefit from new systematic and periodic plant surveys, especially for invasive plant species, and better information on plant species mi-

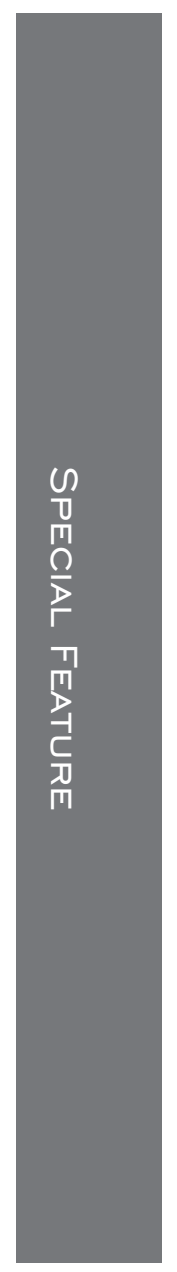

TABLE 2. Models evaluated for native plant species density (NatSpDen).

\begin{tabular}{|c|c|c|c|c|c|c|}
\hline $\begin{array}{l}\text { Model } \\
\text { no. }\end{array}$ & Native plant species density models & $\mathrm{AIC}$ & $\Delta \mathrm{AIC}$ & $\begin{array}{l}\text { Percentage } \\
\text { difference }\end{array}$ & $\begin{array}{c}\text { Adjusted } \\
R^{2}\end{array}$ & $K$ \\
\hline 1 & NatSpDen $=$ biotic, environmental/topographic, human variables & -16691 & 0 & 0 & 0.69 & 15 \\
\hline 2 & NatSpDen $=$ biotic, human variables & -16525 & 165 & 1.0 & 0.67 & 8 \\
\hline 3 & NatSpDen $=$ biotic, environmental/topographic variables $\dagger$ & -16320 & 370 & 2.2 & 0.65 & 9 \\
\hline 4 & NatSpDen $=$ biotic variables & -16174 & 517 & 3.1 & 0.63 & 5 \\
\hline 5 & NatSpDen $=$ environmental/topographic, human variables & -15622 & 1069 & 6.4 & 0.56 & 11 \\
\hline 6 & NatSpDen $=$ human variables & -14553 & 2138 & 12.8 & 0.37 & 5 \\
\hline 7 & NatSpDen $=$ environmental/topographic variables & -14215 & 2475 & 14.8 & 0.29 & 9 \\
\hline
\end{tabular}

Notes: AIC is the Akaike Information Criterion; $K$ is the number of estimable parameters in the model.

$\dagger$ The normalized difference vegetation index, radiation, and land cover were removed from model $3(P>0.15)$. 
TABLE 3. Models evaluated for nonnative (or nonindigenous) plant species density (NISpDen).

\begin{tabular}{|c|c|c|c|c|c|c|}
\hline $\begin{array}{c}\text { Model } \\
\text { no. }\end{array}$ & Nonnative plant species density models & AIC & $\Delta \mathrm{AIC}$ & $\begin{array}{l}\text { Percentage } \\
\text { difference }\end{array}$ & $\begin{array}{c}\text { Adjusted } \\
R^{2}\end{array}$ & $K$ \\
\hline 8 & NISpDen = biotic, environmental/topographic, human variables $\dagger$ & -24055 & 0 & 0 & 0.86 & 12 \\
\hline 9 & NISpDen $=$ bic & -23 & 166 & 0.7 & & \\
\hline 10 & NISpDen $=$ biotic, environmental/topographic variables $\dagger$ & -23435 & 619 & 2.6 & 0.82 & 11 \\
\hline 11 & NISpDen $=$ biotic variables & -23142 & 913 & 3.8 & 0.80 & 5 \\
\hline 12 & NISpDen $=$ NatSpDen (linear model) & -22378 & 1677 & 7.0 & 0.75 & \\
\hline 13 & NISpDen $=$ environmental/topographic, human variables $\dagger$ & -20806 & 3248 & 13.5 & 0.57 & 11 \\
\hline 14 & NISpDen $=$ human variables & -20335 & 3720 & 15.5 & 0.52 & 5 \\
\hline 15 & NISpDen $=$ environmental/topographic variables & -18962 & 5093 & 21.2 & 0.21 & \\
\hline
\end{tabular}

Notes: AIC is the Akaike Information Criterion; $K$ is the number of estimable parameters in the model.

$\dagger$ Variation in elevation, land cover, precipitation, and the normalized difference vegetation index, (NDVI) were removed from model 8; NDVI, crop area, and disturbance were removed from model 9; land cover and precipitation were removed from model 10; radiation and actual evapotranspiration were removed from model $13(P>0.15)$.

grations, persistence, and extirpations at the county scale and at finer resolutions. Despite the needed improvements in the data set, the patterns and relationships discussed below serve as reasonable working hypotheses.

The very high predictability of nonnative species densities at regional scales $\left(R^{2}=0.64-0.98\right.$; Table 4) and subcontinental scales $\left(R^{2}=0.90\right.$; Fig. 3) strongly supports the same global patterns and proposed mechanisms contributing to native plant diversity (Huston 1999, Hawkins et al. 2003, Ricklefs 2004). In the conterminous United States, nonnative plant species diversity can be expected to be greatest in low-latitude areas, in high-precipitation areas, at low elevations, and in warm temperatures, factors associated with "the good life!": low environmental stress, high productivity, and high heterogeneity (assuming bird species density is a good indicator of habitat heterogeneity). It is unlikely that competition, imagined to be a strong force inhibiting invasions at the scale of plant neighborhoods (e.g., Tilman 1999), is a strong force inhibiting inva-

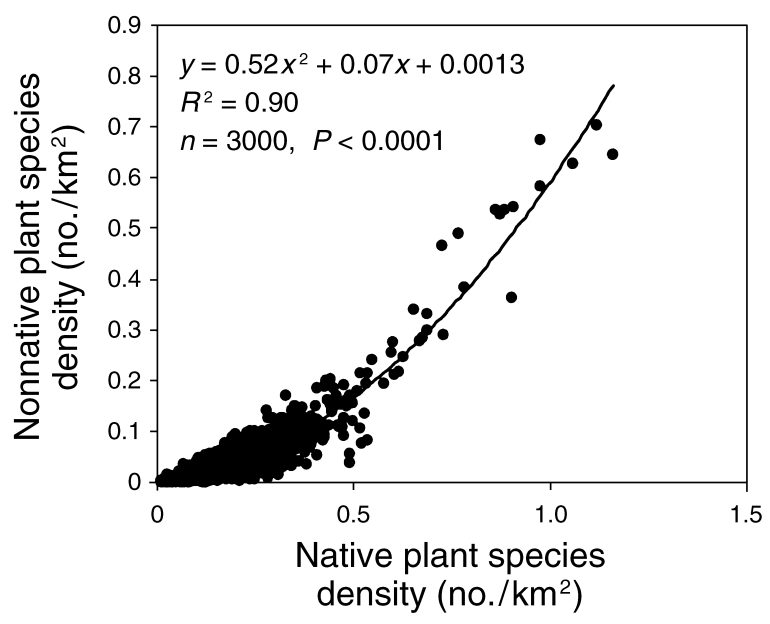

FIG. 3. Relationship between native plant species density and nonnative plant species density in 3000 counties in the United States. Data were log transformed. sions at landscape and regional scales. The more general principal in ecology (and widespread in terms of area) is that regions high in native species richness and density are particularly prone to invasions (Fig. 3, Table 4). Increasing invasions in productive environments would continually add to the regional species pool of nonnative species, facilitating future invasions in productive and less productive environments. Human factors may play an important role in the observed patterns of nonnative plant diversity via initial establishment locations. However, environmental factors may determine the ultimate distributions and densities of nonnative species.

\section{Cautions, Conclusions, and Next Steps}

Local (Ricklefs 2004) and regional determinism may play an extremely important role in the invasion of nonindigenous species because: (1) the strongest predictor of the densities of nonnative plant species was the density of their native cohorts (Fig. 3, Table 4); (2) native and nonnative species densities generally tracked the same factors in a consistent way (Tables 2 and 3); and (3) models that included human factors were not strongly supported by the data using AIC (Table 3). Even stronger than we reported earlier for the richness

TABLE 4. Regional tests of the polynomial model $\left(y=x^{2}\right.$ $+x+c$ ) predicting nonnative plant species density $(y)$ from native plant species density $(x)$ as in Fig. 3.

\begin{tabular}{lcc}
\hline \hline \multicolumn{1}{c}{ State groups } & Adjusted $R^{2}$ & No. counties \\
\hline CA (by itself) & 0.98 & 58 \\
AZ, NM, UT, CO & 0.64 & 140 \\
FL, GA, MS, LA & 0.64 & 125 \\
NY, NH, PA, ME & 0.95 & 155 \\
MT, WY, ND, SD & 0.72 & 195 \\
WA, OR, ID & 0.96 & 118 \\
\hline
\end{tabular}

Note: State abbreviations are: CA, California; AZ, Arizona; NM, New Mexico; UT, Utah; CO, Colorado; FL, Florida; GA, Georgia; MS, Mississippi; LA, Louisiana; NY, New York; NH, New Hampshire; PA, Pennsylvania; ME, Maine; MT, Montana; WY, Wyoming; ND, North Dakota; SD, South Dakota; WA, Washington; OR, Oregon; ID, Idaho. 
of vascular plants in counties (Stohlgren et al. 2003) and a linear model comparing native and nonnative plant species densities (Table 3, model 12), we found additional evidence to support "the rich get richer" pattern (Fig. 3, Table 4). There is little evidence of a saturation of nonnative plant species densities at county, regional, or continental scales. But because the density of nonnative plant species generally tracks hotspots of native plant and bird species diversities and a subset of environmental factors, areas of high native plant and bird species diversity near current invasions should be specifically targeted for early detection and rapid response programs. We need to carefully monitor invasions in species-rich areas.

One next step will be to include information on species identity and characteristics. For example, Brazilian pepper tree, Australian melaleuca, and Asian cogongrass were pre-adapted to the climatic conditions they found in Florida. Climate matching (Huston 1979, 1994, Currie 1991, Rosenzweig 1995) and habitat matching, where nonnative annual plant species target habitats high in native annual plant species (Stohlgren et al. 2005), may support increasing invasions by nonnative species facilitated by trade and transportation. We need to better predict the interactions of species traits and the vulnerability of habitats to invasion. Several nonnative plant species may benefit from continued introduction into many habitats each year by trade and transportation (Reichard and White 2001). This will complicate the development of site-specific predictive models of invasion.

There are many additional factors that could affect the success of nonnative species in species-rich areas including weak competition for resources from native species, use of previously underused resources, or escape from natural predators (see Mack et al. [2000]). Native and nonnative plant species may simply be responding to similarly inviting habitats and resources (Stohlgren et al. 2005a, $b$ ), coexisting due to habitat heterogeneity (Huston 1994), high species turnover, increased pulses of available resources from continued large and small disturbances (D’Antonio et al. 1999), and thus, more opportunities for the establishment of nonnative plants (Abbott 1977, Abbott and Black 1980, Rosenzweig 1995, Stohlgren et al. 1997, 2003). This is the case for plants in Rocky Mountain National Park, Colorado, and throughout the Central Grasslands of the United States (Stohlgren et al. 1999a, 2002). Identifying specific mechanisms and processes associated with invasion is beyond the scope of this correlative study. However, the highly significant nonlinear patterns that we observed (Fig. 3, Table 4) and the highly significant cross-correlations and models are reason for concern.

Disturbances such as wildfire and hurricanes, land use change, and altered disturbance regimes may facilitate invasions. However, many fairly undisturbed areas have been successfully invaded, such as ungrazed grassland sites, tree fall gaps, small-mammal mounds, and throughout many natural areas (Stohlgren et al. $1999 a, b)$.

In many areas, the richness and foliar cover of nonnative plant species are strongly positively correlated (Stohlgren et al. 1998, 1999a, 2003, 2005b), so habitats vulnerable to establishment may also be vulnerable to successful invasion by nonnative species. However, despite the generalized patterns shown here where nonnative plant species have successfully established in native species-rich counties, many nonnative plant species also have been successful in species-poor areas (e.g., cheatgrass in some arid shrublands). Additional research is needed on the multiple factors associated with successful species invasions. Predictive models may be improved by using many of the factors identified here (Tables 1-3, Fig. 3) to begin forecasting where species will move in space and time. Theories pertaining to rates of species invasions will have to accommodate extensive coexistence of native and nonnative species at large spatial scales, lag times, and highly dominant native species or superinvaders in certain habitats (not all species are equivalents [Hubbell 2001]).

\section{ACKNOWLEDGMENTS}

We would like to thank Wanda Manning for supplying avian data, assisting with data management, and obtaining literature sources. The U.S. Geological Survey thanks the many people who contribute data to the program. We thank Greg Newman, Jim Graham, Misako Nishino, and Catherine Crosier for assisting with data management. Helpful comments were provided by Bradford Hawkins, Michael Huston, Ken Burnham, and two anonymous reviewers. Funding was provided by the US Fish and Wildlife Service, NASA Goddard Space Flight Center, and the US Geological Survey Biological Discipline and the National Biological Information Infrastructure. Logistical support was provided by the USGS Fort Collins Science Center and the Natural Resource Ecology Laboratory at Colorado State University. To all we are grateful.

\section{Literature Cited}

Abbott, I. 1977. Species richness, turnover and equilibrium in insular floras near Perth, Western Australia. Australian Journal of Ecology 1:275-280.

Abbott, I., and R. Black. 1980. Changes in species composition of floras on islets near Perth, Western Australia. Journal of Biogeography 7:399-410.

Allen, A. P., J. H. Brown, and J. F. Gillooly. 2002. Global biodiversity, biochemical kenetics, and the energeticequivalence rule. Science 297:1545-1548.

Badgley, C., and D. L. Fox. 2000. Ecological biogeography of North American mammals: species density and ecological structure in relation to environmental gradients. Journal of Biogeography 27:1437-1467.

Bond, W. 1983. On alpha diversity and the richness of the Cape Flora: a study in southern cape fynbos. Pages 337356 in F. J. Kruger, D. T. Mitchell, and J. U. M. Jarvis, editors. Mediterranean-type ecosystems: the role of nutrients. Springer-Verlag, New York, New York, USA.

Burnham, K. P., and D. R. Anderson. 2002. Model selection and multimodel inference: a practical information-theoretical approach. Second edition. Springer, New York, New York, USA.

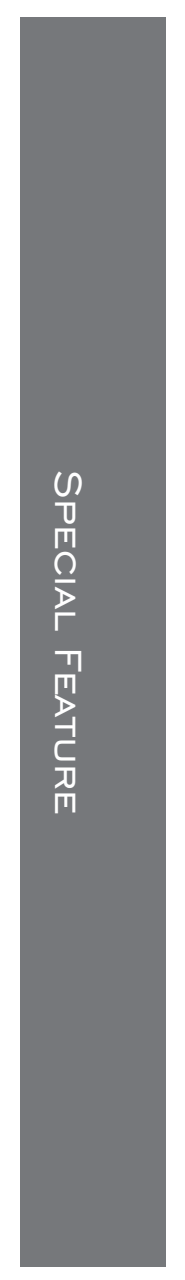


Chong, G. W., R. M. Reich, M. A. Kalkhan, and T. J. Stohlgren. 2001. New approaches for sampling and modeling native and exotic plant species richness. Western North American Naturalist 61:328-335.

Cowling, R. M., P. M. Rundel, P. G. Desmet, and K. G. Esler. 1998. Extraordinarily high regional scale plant diversity in southern Africa arid lands: subcontinental and global comparisons. Diversity and Distributions 4:27-36.

Crosier, C., and T. J. Stohlgren. 2004. Improving biodiversity knowledge with dataset synergy: a case study of non-native plants in Colorado. Weed Technology Supplement S 18: 1441-1444.

Currie, D. J. 1991. Energy and large-scale patterns of animaland plant-species richness. American Naturalist 137:2749.

D’Antonio, C. M., T. L. Dudley, and M. Mack. 1999. Disturbance and biological invasions: direct effects and feedbacks. Pages 413-452 in L. R. Walker, editor. Ecosystems of disturbed ground. Elsevier, New York, New York, USA.

Dobson, A. P., J. P. Rodriguez, W. M. Roberts, and D. S. Wilcove. 1997. Geographic distribution of endangered species in the United States. Science 275:550-553.

Francis, A. P., and D. J. Currie. 2003. A globally consistent richness-climate relationship for angiosperms. American Naturalist 161:523-536.

Gentry, A. H. 1986. Endemism in tropical versus temperate plant communities. Pages 153-181 in M. E. Soulé, editor. Conservation biology: the science of scarcity and diversity. Sinauer, Sunderland, Massachusetts, USA.

Grime, J. P. 1973. Control of species density in herbaceous vegetation. Journal of Environmental Management 1:151167.

Hawkins, B. A., and J. A. F. Diniz-Filho. 2004. "Latitude", and geographic patterns in species richness. Ecography 27: 268-272.

Hawkins, B. A., R. Field, H. V. Cornell, D. J. Currie, J. F. Guegan, D. M. Kaufman, J. T. Kerr, G. G. Mittelbach, T. Oberdorff, E. M. O'Brien, E. E. Porter, and J. R. G. Turner. 2003. Energy, water, and broad-scale geographic patterns of species richness. Ecology 84:3105-3117.

Hindrichson, D. 1997. Humanities and the world's costs: a status report. Amicus Journal 18:16-20.

Hof, J., C. Flather, T. Baltic, and R. King. 2004. Forest and rangeland ecosystem condition indicators: identifying national areas of opportunity using data envelopment analysis. Forest Science 50:473-494.

Hubbell, S. P. 2001. The unified neutral theory of biodiversity and biogeography. Princeton University Press, Princeton, New Jersey, USA.

Huston, M. A. 1979. A general hypothesis of species diversity. American Naturalist 113:81-101.

Huston, M. A. 1994. Biological diversity: the coexistence of species in changing landscapes. Cambridge University Press, New York, New York, USA.

Huston, M. A. 1999. Local processes and regional patterns: appropriate scales for understanding variation in the diversity of plants and animals. Oikos 86:393-401.

Kleidon, A., and H. A. Mooney. 2000. A global distribution of biodiversity inferred from climatic constraints: results from a process-based modeling study. Global Change Biology 6:507-523.

Mack, R. N., D. Simberloff, M. Lonsdale, H. Evans, M. Clout, and F. Bazzaz. 2000. Biotic invasions: causes, epidemiology, global consequences and control. Issues in Ecology 5:1-20.

Myers, N., R. A. Mittermeier, C. G. Mittermeier, G. A. B. da Fonseca, and J. Kent. 2000. Biodiversity hotspots for conservation priorities. Nature 403:853-858.

Neter, J., W. Wasserman, and M. H. Kutner. 1990. Applied linear statistical models: regression, analysis of variance, and experimental designs. Third edition. Irwin, Homewood, Illinois, USA.

O’Brian, E. M. 1998. Water-energy dynamics, climate, and prediction of woody plant species richness: an interim general model. Journal of Biogeography 25:379-398.

Reichard, S. H., and P. S. White. 2001. Horticulture as a pathway of invasive plant introductions in the United States. BioScience 51:103-113.

Ricklefs, R. E. 2004. A comprehensive framework for global patterns in biodiversity. Ecology Letters 7:1-15.

Rosenzweig, M. L. 1992. Species diversity gradients: we know more and less than we thought. Journal of Mammology 73:715-730.

Rosenzweig, M. L. 1995. Species diversity in space and time. Cambridge University Press, Cambridge, UK.

Soulé, M. E. 1991a. Conservation tactics for a constant crisis. Science 253:744-750.

Soulé, M. E. 1991b. Landuse planning and wildlife maintenance: for conserving wildlife in an urban landscape. Journal of the American Planning Association 57:313-323.

Stein, B. A., L. S. Kutner, G. A. Hammerson, L. L. Master, and L. E. Morse. 2000. State of the states: geographic patterns of diversity, rarity, and endemism. Pages 119-157 in B. A. Stein, L. S. Kutner, and J. S. Adams, editors. Precious heritage: the status of biodiversity in the United States. Oxford University Press, New York, New York, USA.

Stohlgren, T. J., D. T. Barnett, C. H. Flather, P. L. Fuller, B. Peterjohn, J. Kartesz, and L. L. Master. 2005a. Species richness and patterns of invasion in plants, birds, and fishes in the United States. Biological Invasions, in press.

Stohlgren, T. J., D. Barnett, and J. Kartesz. 2003. The rich get richer: patterns of plant invasions in the United States. Frontiers in Ecology and the Environment 1:11-14.

Stohlgren, T. J., D. Binkley, G. W. Chong, M. A. Kalkhan, L. D. Schell, K. A. Bull, Y. Otsuki, G. Newman, M. Bashkin, and Y. Son. 1999a. Exotic plant species invade hot spots of native plant diversity. Ecological Monographs 69: 25-46.

Stohlgren, T. J., K. A. Bull, Y. Otsuki, C. A. Villa, and M. Lee. 1998. Riparian zones as havens for exotic plant species. Plant Ecology 138:113-125.

Stohlgren, T. J., G. W. Chong, M. A. Kalkhan, and L. D. Schell. 1997. Rapid assessment of plant diversity patterns: a methodology for landscapes. Environmental Monitoring and Assessment 48:25-43.

Stohlgren, T. J., G. W. Chong, L. D. Schell, K. A. Rimar, Y. Otsuki, M. Lee, M. A. Kalkhan, and C. A. Villa. 2002. Assessing vulnerability to invasion by nonnative plant species at multiple spatial scales. Environmental Management 29:566-577.

Stohlgren, T. J., C. Crosier, G. Chong, D. Guenther, and P. Evangelista. 2005b. Life-history habitat matching in invading non-native plant species. Plant and Soil, in press.

Stohlgren, T. J., D. A. Guenther, P. H. Evangelista, and N. Alley. 2005c. Patterns of plant species richness, rarity, endemism, and uniqueness in an arid landscape. Ecological Applications 15, in press.

Stohlgren, T. J., Y. Otsuki, C. Villa, M. Lee, and J. Belnap. 2001. Patterns of plant invasions: a case example in native species hotspots and rare habitats. Biological Invasions 3: 37-50.

Stohlgren, T. J., L. D. Schell, and B. Vanden Heuvel. 1999 b. How grazing and soil quality affect native and exotic plant diversity in Rocky Mountain grasslands. Ecological Applications 9:45-64.

Tilman, D. 1999. The ecological consequences of changes in biodiversity: a search for general principles. Ecology 80: $1455-1474$. 
Venevsky, S., and I. Veneskaia. 2003. Large-scale energetic and landscape factors of vegetation diveristy. Ecology Letters 6:1004-1016.

von Humboltd, A. 1808. Ansichten der Natur mit wissenschaftlichen Erlauterungen. J. G. Cotta, Tübingen, Germany.
Wilcove, D. S., D. Rothstein, J. Dubow, A. Phillips, and E. Losos. 1998. Quantifying threats to imperiled species in the United States. Bioscience 48:607-615.

Zar, J. H. 1974. Biostatistical analysis. Prentice-Hall, Englewood Cliffs, New Jersey, USA.

\section{APPENDIX}

A table presenting species richness and ancillary data used in this analysis is available in ESA's Electronic Data Archive: Ecological Archives E086-121-A1. 